\title{
Engineering Study for a Full Scale Demonstration of Steam Reforming Black Liquor Gasification at Georgia-Pacific's Mill in Big Island, Virginia
}

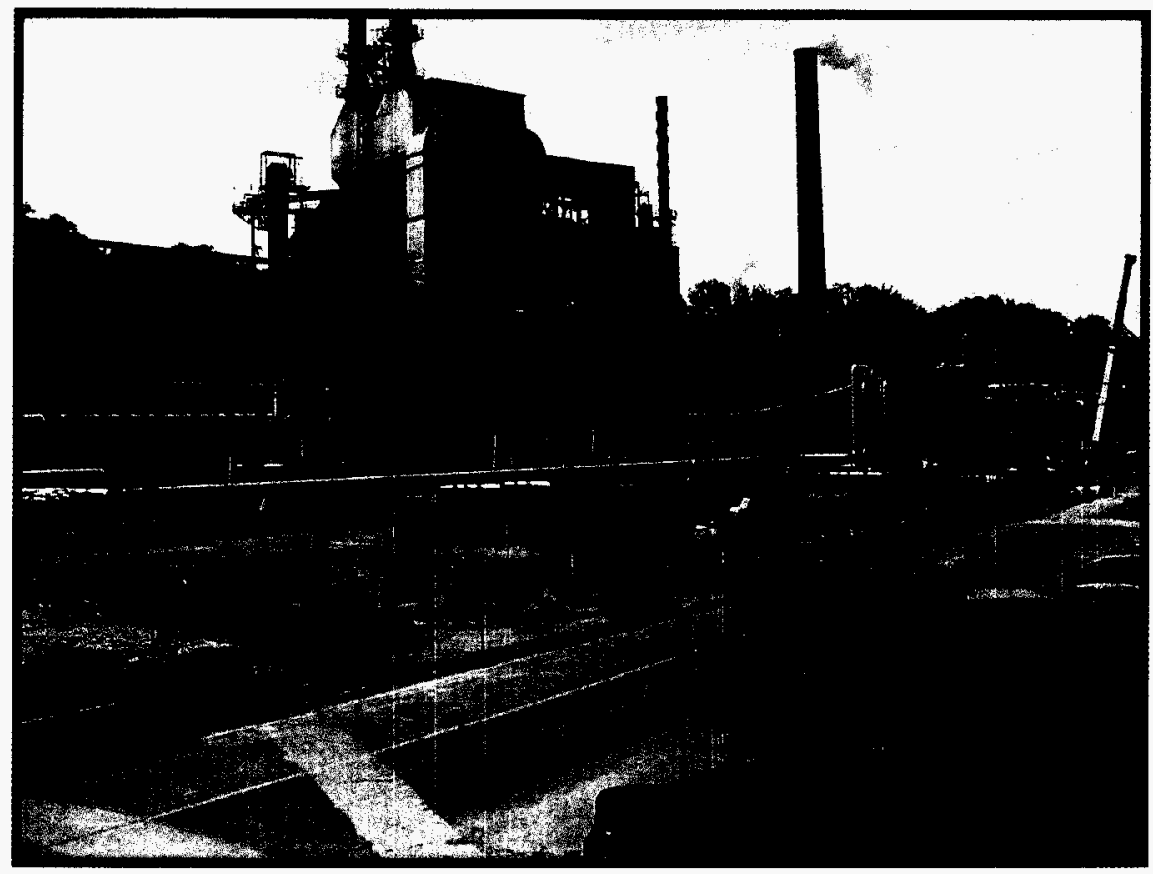

February 04, 2002

GP. GeorgiaPacific 


\title{
Final Report
}

\section{Engineering Study for a Full Scale Demonstration of Steam Reforming Black Liquor Gasification at Georgia-Pacific's Mill in Big Island, Virginia}

\author{
Department of Energy \\ DE - FC07-99ID13818
}

For more information contact:

Robert DeCarrera

Georgia-Pacific Corporation P.O. Box 105605

Atlanta, Georgia 30348-5605

David Robertson

U.S. Department of Energy

Idaho Operations Office

850 Energy Drive, MS-1220

Idaho Falls, ID 83401-1563
Mike Ohl

Georgia-Pacific Corporation

9363 Lee- Jackson Highway

Big Island Virginia 24526

Robert Gemmer

U.S. Department of Energy

Office of Industrial Technology

1000 Independence Ave., SW, MS-6B-025

Washington, DC 20585

This report was prepared with the support of the U.S. Department of Energy (DOE) Award No. DE-FC07-99ID13818. However, any opinions, findings, conclusions, or recommendations expressed herein are those of the author(s) and do not necessarily reflect the view of DOE. 


\section{INTRODUCTION}

This report is a summary of the activities and results of an engineering study conducted to determine the feasibility of utilizing the MTCI PulseEnhanced ${ }^{\text {TM }}$ Steam Reforming technology as a replacement for the chemical recovery equipment at Georgia-Pacific Corporation's mill in Big Island, Virginia. The main participants in the study were:

- Georgia-Pacific - Atlanta, GA and Big Island, VA - Study leader and facility owner

- StoneChem, Inc. - Baltimore, MD- Licensee for the MTCI technology

- Industra, Inc. - Portland, OR - Consulting engineering for the steam reformer

- AGRA Simons, Inc. - Atlanta, GA - Consulting engineering for the recovery boiler cost estimate

- Fluor Daniel, Inc. - Greenville, SC and Aliso Viejo, CA - Steam reformer technology risk assessment

\section{EXECUTIVE SUMMARY}

The engineering study was conducted from June 1999 through June 2001. The purpose of the study was to define the project requirements for the installation of a demonstration project in Big Island, Virginia. The study was to determine the scope, cost, benefits and risks associated with the project. As part of the study, the alternative to the new technology, a Conventional recovery boiler, was also studied. The study would also determine if the project was feasible from both a technical and economic prospective and if the project could compete with conventional technology.

The study was divided into multiple tasks. These included liquor trials at StoneChem's Process Development Unit (PDU), preliminary engineering performed by Industra, an estimate of the cost to install an equivalent recovery boiler by AGRA Simons, and a technology risk assessment by Fluor Daniel. In June 2000, the agreement was amended to include additional tasks to modify StoneChem's PDU to better reflect a commercial unit and perform additional liquor testing.

The work was completed as scheduled. The overall results of the study indicated that installation of the first steam reforming chemical recovery system was higher cost than an equivalent recovery boiler system. It is expected, that as the technology gaps are eliminated, future installations will be possible at approximately the same cost as a conventional recovery boiler system. The energy efficiency of the reformer system was better than the recovery system, while the environmental performance appeared to surpass the recovery boiler system. The technological risk and project risk associated with the installation of the reformer system were significantly higher for the reformer system. Based on the findings of the Engineering Study, Georgia-Pacific elected to go forward with a project for the demonstration of the technology. This decision was contingent on a commitment from DOE to co-fund the demonstration project. In February 2001 Georgia-Pacific submitted a proposal to DOE for the implementation of the demonstration project. 


\section{TABLE OF CONTENTS}

Introduction 3

Executive Summary 3

Abstract $\quad 5$

History 6

Background of the Technology 7

Project Scope $\quad 8$

Project Objectives $\quad 9$

Potential Benefits to the Industry 10

Expected Benefits for the Big Island Mill 11

Technology Description $\quad 14$

Project Environmental Process $\quad 18$

Results of Liquor Testing $\quad 20$

Project Schedule \& Cost 22

Viability 23

Technology Gaps $\quad 24$ 


\begin{abstract}
Georgia-Pacific Corporation performed an engineering study to determine the feasibility of installing a full-scale demonstration project of steam reforming black liquor chemical recovery at Georgia-Pacific's mill in Big Island, Virginia. The technology considered was the PulseEnhanced ${ }^{\mathrm{TM}}$ Steam Reforming technology that was developed and patented by Manufacturing and Technology Conversion, International (MTCI) and is currently licensed to StoneChem, Inc. for use in North America. Pilot studies of steam reforming have been carried out on a 25-ton per day reformer at Inland Container's Ontario, California mill and on a 50-ton per day unit at Weyerhaeuser's New Bern, North Carolina mill.
\end{abstract}

This engineering study included all of the necessary activities to determine the feasibility of the demonstration project. The demonstration project will include engineering, construction, startup, and operation of a 400,000 pounds per day black liquor solids steam reformer plant including reformer reactor, gas cleanup system, heat recovery, and chemical recovery. The demonstration project will replace existing smelters and provide the entire chemical recovery capacity for the Big Island mill. Excess product gas from the steam reformer will be burned in a heat recovery unit to produce 600 psig process steam to replace a portion of the steam currently generated by a higher cost natural gas fired boiler. This represents an energy recovery opportunity currently not available to Big Island, other non-sulfur semi-chemical mills or sulfate mills.

The Big Island Mill converted to non-sulfur caustic-carbonate pulping in 1972, and has extensive experience in processing the high viscosity and difficult burning sodium based black liquor. Pilot tests on Big Island black liquor at MTCI's facility in Baltimore, Maryland have shown the capability of the steam reforming process and confirmed the potential energy and environmental benefits. The Big Island mill represents a unique opportunity to demonstrate the capabilities and applicability of the Steam Reformer Gasification Technology for chemical recovery in the Pulp and Paper Industry. The extremely low sulfur chemistry of this facility provides a lower risk opportunity for demonstration of the technology, while the size of the mill provides the opportunity for this process to provide complete chemical recovery. Additionally, sulfur recovery equipment will be installed to enable the demonstration project to conduct full-scale trials on Kraft black liquor. Previous pilot studies indicate that steam reforming is a superior process for the recovery of Kraft black liquor. 


\section{HISTORY}

In November 1994, the American Forest \& Paper Association (AF\&PA) issued "Agenda $2020 \mathrm{~A}$ Technology Vision and Research Agenda for America's Forest, Wood and Paper Industry". The association, with assistance from research institutions and organizations, developed this vision. This document presented the industry's perspective of the technology-related issues that must be addressed to accomplish the industry's vision of the future. The long-range research agenda identified six high priority areas with research needs. One of these areas was "Energy Performance", which identified "Biomass and Black Liquor Gasification" as technologies which "...should be commercialized to allow improvement in efficiency and reduction in capital intensity"'.

In July 1998, AF\&PA issued "American Forest, Wood and Paper Industry Gasification Combined Cycle Initiative" stating "Three joint Forest Products Industry-Department of Energy (DOE) projects have so far been endorsed by both the Chief Technology Officers Working Group and the CEO Climate Change Options Advisory Group of the American Forest \& Paper Association as appropriate to demonstrate biomass and black liquor gasification."2 One of these projects was the demonstration of the MTCI/StoneChem PulseEnhanced ${ }^{\mathrm{TM}}$ Steam Reforming Process at Georgia-Pacific's mill in Big Island, VA.

\footnotetext{
'Agenda 2020 A Technology Vision and Research Agenda for America's Forest, Wood and Paper Industry, American Forest \& Paper Association, November, 1994

${ }^{2}$ American Forest, Wood and Paper Industry Gasification Combined Cycle Initiative, American Forest \& Paper Association, July 11, 1998 


\section{BACKGROUND OF THE TECHNOLOGY}

The recovery process is an essential component of a pulp and paper mill operation from both an economic and an environmental aspect. Chemicals used in the pulping process are recovered and spent liquor organic solids are converted to energy (typically process steam). The conventional recovery boiler has been the predominant technology; however, fluidized bed combustors have also been used successfully in some segments of the industry. Both technologies have inherent deficiencies including low thermal efficiencies, high capital and maintenance costs, and various operational problems. The conventional recovery unit has the additional potential for smelt-water explosions although the industry has made significant progress in minimizing this potential.

Gasification of black liquor represents a new and better approach for the chemical recovery process and eliminates many of the deficiencies of the conventional recovery and fluid bed combustion technologies. Gasification benefits include increased efficiency in energy conversion and chemical recovery, elimination of the smelt-water explosion hazard, reduced maintenance costs, and significantly lower environmental emissions including particulate, TRS, NOx, VOC, and greenhouse gases. The benefits are particularly attractive to semi-chemical nonsulfur processes that require higher cost auxiliary fuel to sustain combustion of the black liquor.

The steam reforming technology is ideally suited to the conversion of a variety of variable moisture content organic feedstocks, such as black liquor. Carbon conversion efficiency to gas can be high, typically 95 percent. The MTCI Steam Reformer technology is unlike the other gasification processes currently available. The process employs indirect PulseEnhanced ${ }^{\mathrm{TM}}$ heating of a steam-fluidized bed of sodium carbonate solids. This process produces an endothermic reaction converting black liquor organics to a gas in the absence of air or oxygen at temperatures below those required for smelt formation. This approach avoids the shortcomings of exothermic reactions found in other gasification processes that utilize higher temperatures and produce smelt. MTCI has carried out studies of spent liquor reforming in a 0.5 ton per day black liquor solids pilot unit since 1990 . Successful pilot trials have been conducted steam reforming Big Island black liquor for 108 continuous hours at this facility. Tests on the product gas from the pilot trials have confirmed the potential energy and environmental benefits. A 25-ton per day black liquor solids reformer was operated on mill sludge and imported black liquor at Inland Container Corporation's Ontario, California, mill in March 1992. A nominal 50-ton per day black liquor solids pilot demonstration plant began operation at Weyerhaeuser's New Bern, North Carolina, Kraft mill in the spring of 1994. A 500-hour continuous test was successfully completed at New Bern in August 1995. Although neither is in current operation, the results from both units identified improvements that will be incorporated into the design of the full-scale units.

A project team was formed to analyze the alternatives for the Georgia-Pacific mill in Big Island to meet the requirements of the EPA Cluster Rule MACT I regulations and MACT II proposed regulations. After analyzing various options, two project alternatives were determined to be economically viable and capable of meeting the requirements of the project. A conventional recovery boiler option could meet the project objectives with proven technology and demonstrated safety, environmental and energy performance. A steam reformer, while not a 
proven technology for this application, offers to meet the project requirements with better safety, environmental and energy performance than a conventional recovery boiler. Since the steam reformer technology is not proven in the scale required for the Big Island demonstration, the project has considerable commercial risk for Georgia-Pacific.

\section{PROJECT SCOPE}

The engineering study consisted of all of the activities required to completely define the scope of the full-scale demonstration project and to secure the necessary funding. The engineering study included activities necessary to obtain permits, assess the project risk and evaluate alternatives. The project alternative chosen from this study is a full-scale steam reformer demonstration project. This demonstration project will install a steam reformer and associated equipment to process all of the black liquor ( 400,000 pounds of black liquor solids per day) from the pulping process at the Georgia-Pacific mill in Big Island, Virginia. The steam reformer and associated equipment will operate with environmental emissions at or below the limits set by the environmental permit. The equipment installed will maximize the recovery of energy and chemicals while producing a sodium carbonate solution suitable for use in the pulping process. 


\section{PROJECT OBJECTIVES}

\section{Task 1 - Preliminary Engineering}

Provide a detailed engineering report that would include a detailed project scope, a cost estimate for the project of plus or minus $10 \%$ accuracy, and a detailed project implementation schedule. Identify alternatives and quantify cost and benefit.

\section{Task 2 - Liquor Test Phase 1}

Provide a report of liquor pilot plant trial of 4 weeks duration to determine the environmental performance, process limits and predicted process values for the technology. Provide bed solids from pilot steam reformer to be used in Task 6 (liquor filtration trials).

\section{Task 3 - Technology Risk Assessment}

Determine and provide a report quantifying the risk of the steam reformer technology and process. Identify risk mitigation steps to be required in the second phase of the project.

\section{Task 4 - Environmental Modeling and Permit}

Provide the engineering and modeling required to obtain an environmental permit for the second phase of the project.

\section{Task 5 - Liquor Test Phase 2}

Provide liquor pilot plant trial of 2 weeks duration to determine the sizing of downstream equipment components using variations of fuel mixture.

\section{Task 6 - Liquor Filtration Trials}

Determine and provide a report of the performance of various liquor filtration schemes on the quality of the process chemicals. Provides sizing, specification and cost estimate of the filtration equipment required in the second phase of the project.

\section{Task 7 - Site Soil Investigation}

Provide subsurface soil investigation to determine the cost and design requirements of foundations in the second phase of the project.

\section{Task 8 - Procurement Specifications for Equipment}

Determine and provide detailed equipment specifications to obtain competitive bids for the major equipment required in the second phase of the project.

\section{Task 9 - Georgia-Pacific Project Management}

Provide project management services and coordinate the various activities. Evaluate task results and adjust as required. Prepare the final report for this phase of the project and determine the feasibility of proceeding with Phase 2 . Prepare the necessary project documentation so information is available to obtain funding for Phase 2 from GeorgiaPacific and from DOE.

\section{Task 10 - Georgia-Pacific Travel and Expenses}

Travel and expenses associated with Phase 1 of the project. Includes travel to Baltimore for assisting with the liquor trials, travel to various liquor filter manufacturer's facilities, and travel to periodic project review meetings. 


\section{EXPECTED BENEFITS TO THE INDUSTRY}

Successful completion of the engineering study was necessary prior to the implementation of the full-scale demonstration project. The completion of the engineering study provided performance data on a new technology to help define the process and equipment. The study also addressed risks associated with this new technology and possible mitigation procedures to reduce this risk. The study identified existing commercially proven auxiliary equipment that can be adapted for use with this technology.

Successful completion of the full-scale demonstration project will prove this technology to be capable of providing the full chemical recovery capacity for a mill. The project will demonstrate the reliability and operational flexibility of the technology and all of the associated equipment. Once the technology is demonstrated, the industry can apply this at other facilities to obtain better energy conversion, improved safety and environmental performance. Once this and other gasification technologies are demonstrated, they can be deployed throughout the industry.

As part of the American Forest and Paper Association's (AF\&PA) Agenda 2020, these benefits have been identified. If proven, these technologies offer great potential for improved capital effectiveness, energy efficiency, environmental performance, global competitiveness and safety in the forest, wood and paper industry. These advantages will be gained from:

- The ability to increase electrical power production capability by up to $300 \%$;

- Providing the potential to positively impact green house gas emissions by over 30 million metric tons of carbon per year;

- Making available these technology options early enough for the majority of U.S. industry to utilize them in normal capital replacement decisions; and

- Providing U.S. facilities with significantly more effective and efficient powerhouses compared to currently growing segments of the global industry, such as southeast Asia.

A key impetus to commercialize biomass and black liquor technologies is the ability to fire the product gases in a gas turbine and to use the gas turbine exhaust, which is at about $1000^{\circ} \mathrm{F}$, to raise steam that can be passed through a steam turbine to generate additional electric power. In recent years, the industry has become a significant user of gas turbines as it has increased the amount of power generated on mill sites. Where this has occurred, it provides the basis for partial or complete replacement of natural gas with syngas from black liquor and biomass as natural gas prices increase. In spite of these trends, there is still a substantial and growing amount of power purchased from utilities. Gasification combined cycle has the potential for greatly increasing the amount of electric power generated per unit of fuel.

For example, if one takes the black liquor and hog fuel generated in a 1,500 ton-per-day integrated Kraft mill, it is possible to generate about $70 \mathrm{MW}$ of power using the current technology of a conventional recovery boiler, a combination boiler, and a steam turbine generator. Replacing the conventional recovery boiler with an integrated gasification combined cycle (IGCC) black liquor system increases the potential power generation to nearly $200 \mathrm{MW}$ The same black liquor and hog fuel supplied to a combination of black liquor and biomass gasification in IGCC configuration can generate nearly $300 \mathrm{MW}$ of power (approximately a $300 \%$ and $400 \%$ increase, respectively). The efficiency gain depends on the specific 
configuration examined; but typically, the overall cycle efficiency of an IGCC plant can be up to $10 \%$ higher than a conventional cycle.

If proven to be economically and commercially viable, biomass and black liquor gasification combined cycle technologies offer tremendous opportunities for this industry to make a positive contribution to the reduction of greenhouse gas emissions. Initial estimates indicate that, if fully implemented, these technologies have the potential to reduce carbon emission by 30 to 60 million metric tons per year, depending on whether the fossil fuel displaced is natural gas or coal. Significantly less than $10 \%$ of the industry's boilers would have to transition to the new technology to achieve a $7 \%$ reduction goal for the industry. These impacts are graphically represented below.
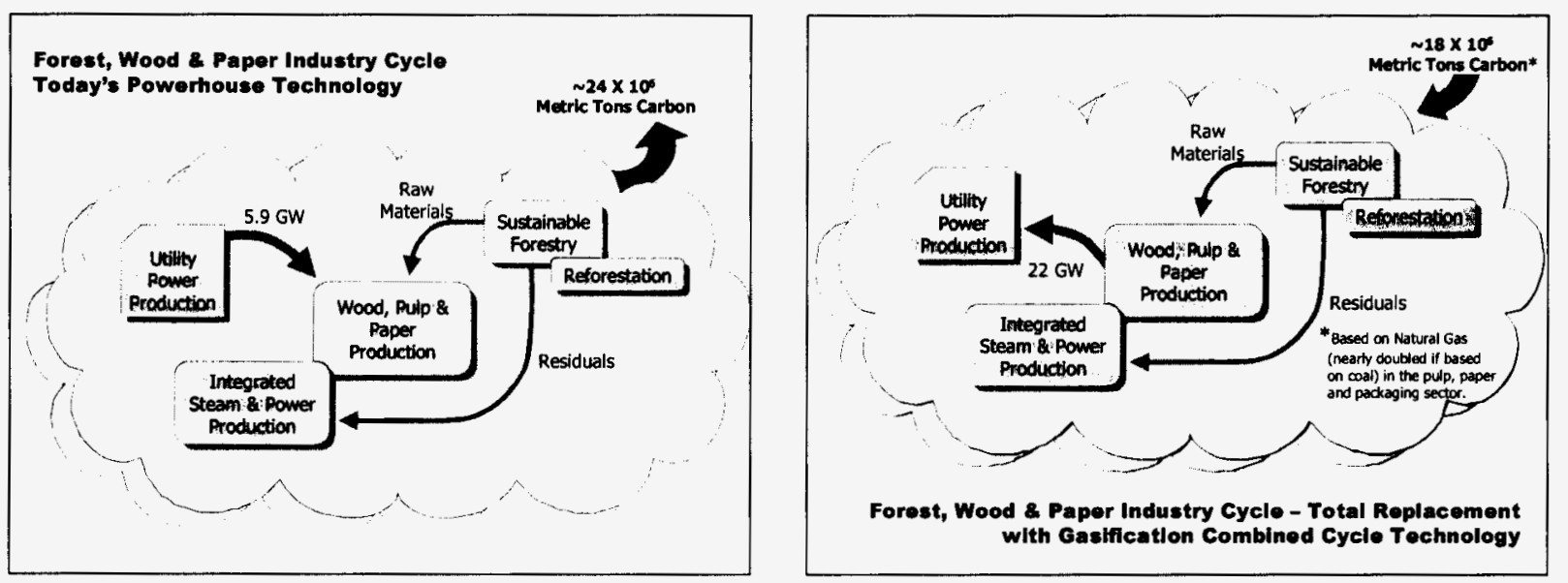

Furthermore, these technologies are believed to have crosscutting applications for other energy intensive industries, such as chemicals, petrochemicals, utilities and refining. By demonstrating these technologies in the forest products sector where there is a high likelihood of success, the Department of Energy-along with key gasification technology suppliers-could help facilitate the transfer of the technology to other potential applications. This would expand the potential for improved energy efficiency and environmental performance in other sectors.

As stated above, the industry has recognized the advantages for itself and for the Nation of biomass and black liquor gasification technologies since the late 70's. Since this time, it has worked with the DOE and others to bring these technologies to commercial reality. Safety, energy efficiency, capital effectiveness and global competitiveness have been consistent drivers for the advancement of these technologies. ${ }^{2}$

\footnotetext{
${ }^{2}$ American Forest, Wood and Paper Industry Gasification Combined Cycle Initiative, American Forest \& Paper Association, July 11, 1998
} 


\section{BENEFITS TO THE BIG ISLAND MILL}

The project benefits expected by the Big Island mill are largely based on the results of pilot testing and the projected operation of the demonstration plant. Since the alternative project options for bringing the Big Island recovery system into compliance with the MACT II regulations were reduced to two viable options, the benefits to the mill are listed on a comparative basis between the options. The only viable options were the Steam Reformer or a Recovery Boiler. The original feasibility study eliminated other compliance options for Big Island.

The benefits are broadly categorized as improved energy performance, improved environmental performance, improved chemical recovery, reduced operating cost, and improved safety performance. Although the actual predicted savings are not included in this report, the relative comparison can be used to determine potential benefits for future similar applications.

The Energy Performance of both the steam reformer and recovery boiler is predicted to be approximately equal. A number of trade-offs were made in this demonstration that reduce the steam reformer energy efficiency. Some of these may not be required in future projects. For this demonstration, the vessel design chosen is cylindrical which is considered to be a lower risk geometry. By using a cylindrical designed vessel, two vessels are required instead of one rectangular geometry vessel. The result is that more fluidizing steam is required and a higher heat loss to the atmosphere is expected. The recovery boiler will deliver $38,000 \mathrm{mmbtu} /$ year more energy to the mill than the steam reformer. The drawback with the recovery boiler energy performance is the need for auxiliary fossil fuel. It is estimated that fossil fuel (natural gas) equivalent to about $10 \%$ of the total heat input will be required to ensure the stable combustion of the lack liquor as well as complete destruction of VOC's in the upper furnace.

The Environmental Performance of the steam reformer is predicted to be significantly better than the recovery boiler. The chart below provides a comparison for emissions.

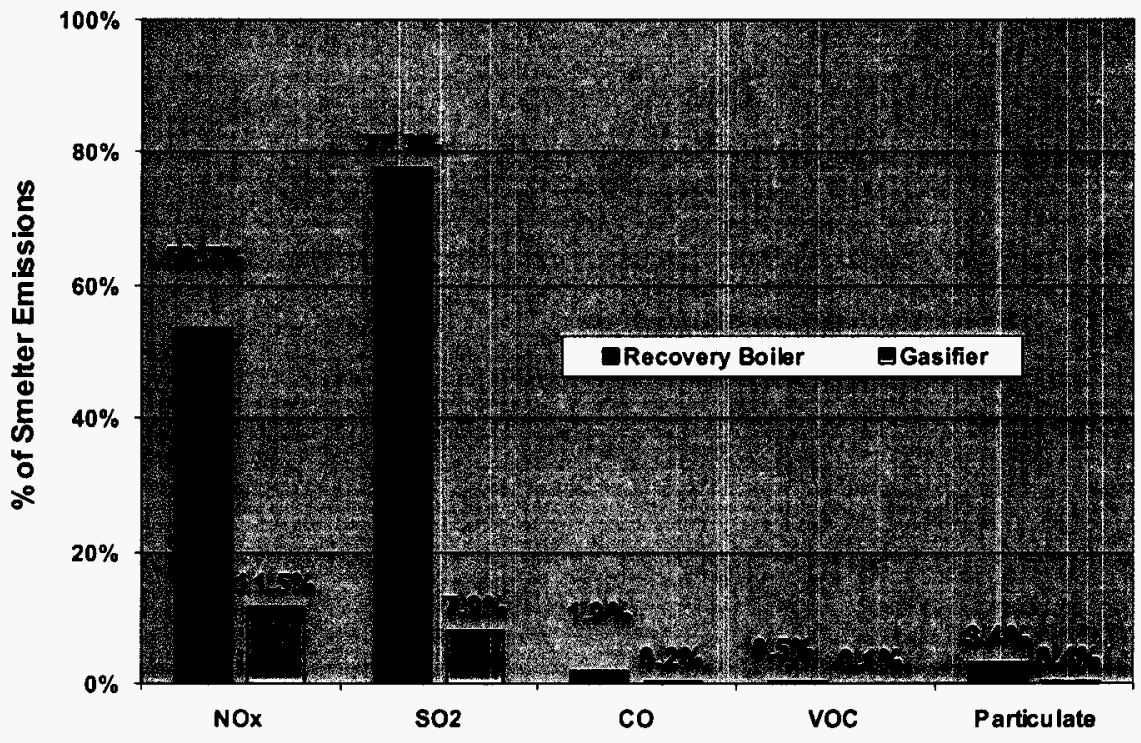


The Chemical Recovery of the steam reformer process is more efficient than the recovery boiler process. It is estimated that the steam reformer process will reduce typical soda loss in this mill by close to 2 pounds per ton of pulp produced as compared to the recovery boiler option.

The mill's Operating Cost will be reduced with the steam reformer process due to the lower operations staffing required by the process. The recovery boiler process requires one more operator per shift than the steam reformer process. It is also predicted that the maintenance cost of the recovery boiler will be $20 \%$ per year higher than for the steam reformer.

The improvement in Safety Performance of the steam reformer over the recovery boiler is difficult to assess. Although the steam reformer does not have the potential for smelt-water reactions, the recovery boiler safety performance has improved significantly in recent history. Since the steam reformer process has not been through the detailed engineering and formal hazard evaluation and review processes, the actual safety performance cannot be quantified. 


\section{TECHNOLOGY DESCRIPTION}

\section{Process Overview}

The PulseEnhanced ${ }^{\mathrm{TM}}$ Steam Reformer is designed to process spent liquor and recover its chemical and energy value. A simplified flow diagram is presented in Figure 1. The recovered chemicals are in the form of sodium carbonate and sulfide/carbonate liquors. The recovered energy is in the form of process steam.

Figure 1: Simplified Flow Diagram

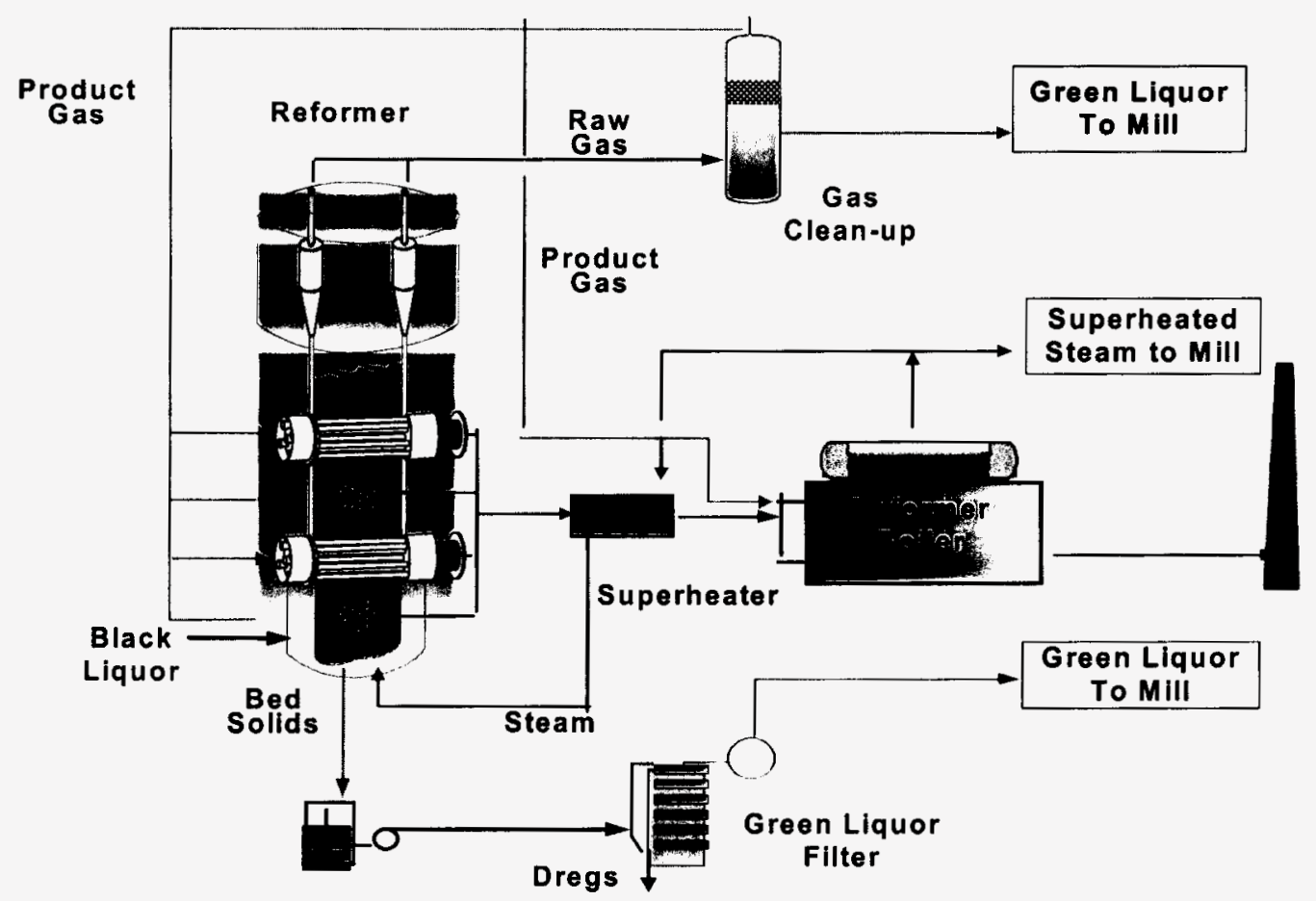

\section{Steam Reforming}

The recovery of chemicals and energy from spent liquor is effected by an endothermic indirectly heated steam reforming process. Steam reforming is an efficient method for the recovery of the energy value of organics in the liquor, resulting in the generation of a hydrogen-rich, mediumBtu product gas. The energy value of the product gas is simply equal to the sum of the heat applied for the endothermic reaction and the energy value of the organics contained in the liquor. This approach avoids the shortcomings of exothermic reactions found in conventional incineration or partial oxidation and autothermal gasification processes which are less efficient, smelt-laden and can form undesirable alkali silicates. Neither direct combustion nor alkali salt smelt formation occurs in the StoneChem steam reforming process. This makes the StoneChem process uniquely suited for the chemical and energy recovery of spent liquors from virtually any fiber and cooking chemistry source. 


\section{Steam Reformer Subsystem}

The steam reformer is a bubbling bed, fluidized with superheated steam (Figure 2). The steadystate bed maintains a mean particle size of approximately 300 microns and is comprised of alkali carbonate, residual carbon and non-process elements such as calcium and silicon. Superheated fluidization steam and recycled product gas are supplied to the distribution headers and bubble caps with sufficient pressure drop to maintain uniform fluidization across the cross-section of the vessel.

Figure 2: $\underline{\text { PulseEnhanced }}{ }^{\mathrm{TM}}$ Steam Reformer

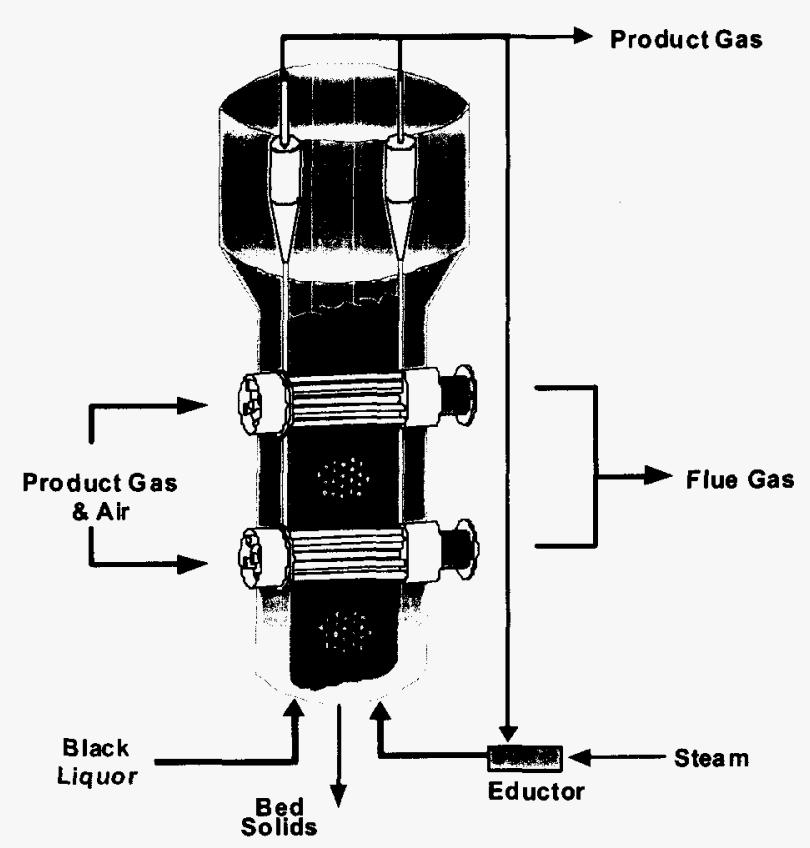

Resonance tubes of the pulsed jet heater module (Figure 3) serve as efficient sources of heat supply to support the endothermic steam reforming reaction for the liquor. The resonance tubes of the pulsed heater modules are mounted perpendicular to the fluidization steam flow to enhance the heat transfer between the resonance tube walls and the fluid-bed particles. Overall, utilization of the pulsed heater reduces the required surface area for heat transfer and reduces the size and capital cost of the reformer. 
Figure 3: Pulsed Jet Heater Module

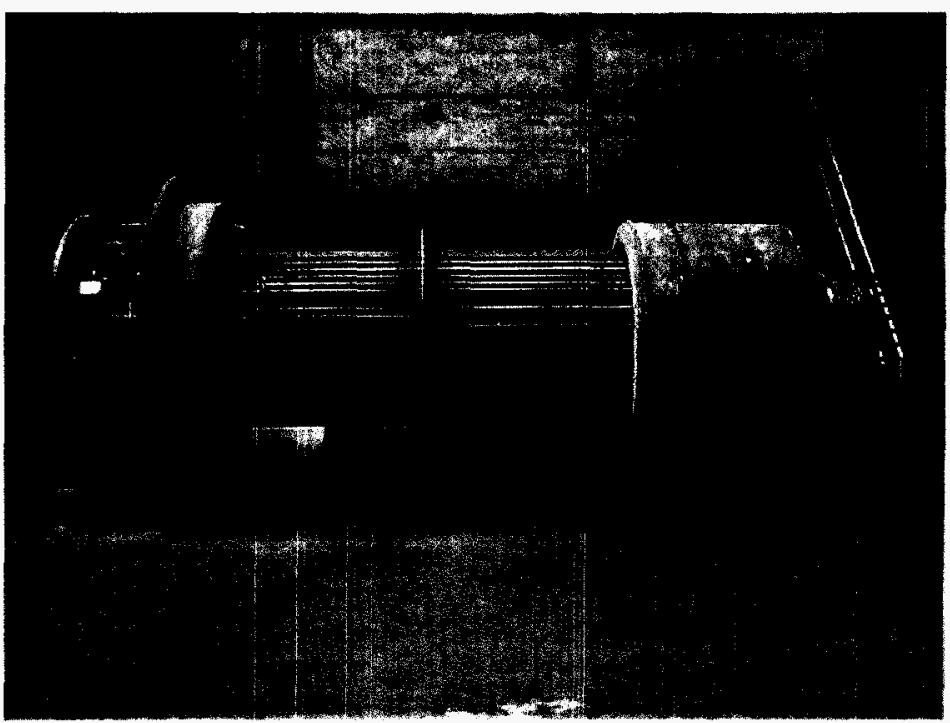

The design of the pulsed heaters is chosen to maximize liquor throughput in the steam reformer by employing excess air in the pulsed combustion chamber. This also reduces plant capital costs while improving efficiency and lowering emissions. In this case, the combustion processes are designed taking full advantage of the need for steam. The pulsed heaters will be optimally tuned for the stoichiometry requirements of this combustion process.

Spent liquor is pumped into the reformer via dual-fluid injectors to provide uniform distribution of the liquor across the cross-section of the bed. The liquor injector design provides a thin film coating of bed particles to enhance reaction rates (high surface-to-mass ratio) and carbon conversion.

Superheated steam reacts endothermically with the carbonaceous components (predominantly dissolved lignin) of the black liquor to produce hydrogen and carbon monoxide fuel gases:

$$
\mathrm{H}_{2} \mathrm{O}+\mathrm{C}+\text { Heat }=\mathrm{H}_{2}+\mathrm{CO} \text { (steam reforming) }
$$

Water-gas shift reactions also occur simultaneously with the steam reforming reactions to yield additional hydrogen and carbon dioxide:

$$
\mathrm{H}_{2} \mathrm{O}+\mathrm{CO}=\mathrm{H}_{2}+\mathrm{CO}_{2} \quad \text { (water-gas shift) }
$$

Sulfur present in the feed liquor is reduced to hydrogen sulfide gas $\left(\mathrm{H}_{2} \mathrm{~S}\right)$ and joins the product gas exiting the reformer. The alkali value of the liquor is carbonated by $\mathrm{CO}_{2}$ to form sodium carbonate and potassium carbonate, which remain as solid components in the fluid bed. As a result, the steam reforming process effects a complete separation of the sulfur-value of the black liquor from the alkali value. 
The steam reformer subsystem includes a superheater to superheat the fluidization steam before it enters the reformer. The superheater employs a portion of the sensible heat in the pulsed heater flue gas stream to superheat the steam. This reduces the heat load in the reactor, thereby reducing the number of heater modules required for the liquor processing throughput.

Entrained bed solids separation and return is accomplished in the steam reformer subsystem by high efficiency, low maintenance and high reliability cyclones. The design employed for these components is identical to that used in catalytic crackers by the refinery industry. The cyclones efficiently capture small particles and return them to the bed for inventory control and additional reaction.

\section{Chemical Recovery}

The alkali, which includes sodium and some potassium, reports to the reformer bed as a dry form of carbonate. By dissolving, washing and filtering the bed solids, a "clear" alkali carbonate solution is produced. The filter cake contains any unreacted carbon as well as insoluble nonprocess elements (NPEs) such as calcium and silicon. The carbon cake can be discarded as a "dregs" waste.

\section{Alkali Extraction and Recovery Subsystem}

The function of the alkali extraction and recovery subsystem is to extract and recover the alkali chemicals from the reformer bed solids. The alkali chemicals report to the bed as dry carbonates. The unreacted carbon and NPEs also report to the bed as insoluble components. The separation of the alkali from insolubles is accomplished by washing and filtering of the bed solids. Countercurrent washing is used to maximize the recovery of the alkali value. The wash water is recycled as a source of water for the mix tank. The alkali extraction system exports the alkali to the mill in the form of a clear sodium carbonate solution for use in the pulp mill. The filter cake is discarded.

\section{Gas Cleanup and Sulfide Recovery Subsystem}

The function of the gas clean-up and sulfide recovery subsystem is to remove particulate, condense the steam and recover the sulfur value from the product gas.

Following the HSRG, the gas is quenched, saturated with water and scrubbed of particulate when contacted with recirculated fluid in a high energy venturi. A small bleed stream containing condensed organics is discharged to the mill's wastewater effluent system.

The gas is then further cooled by countercurrent contact with recirculated liquor in a packed tower. The recirculated liquid is cooled in a non-contact heat exchanger. A bleed stream containing condensed organics is discharged to the mill's wastewater effluent system.

The cooled and cleansed gas enters the green liquor column. The column is a multistage countercurrent, packed scrubber. Hydrogen sulfide from the product gas is absorbed with a combination sodium carbonate and caustic solution to produce green liquor for the process. The green liquor column is equipped with a demineralized water polisher to prevent alkali carryover to the pulsed heaters and other burning equipment. 


\section{Energy Recovery}

While self sufficient on its own energy needs (steam and fuel gas), StoneChem's process provides maximum flexibility in the recovery of export energy from spent liquor. For Big Island, recovered energy is in the form of $600 \mathrm{psig}, 750^{\circ}$ superheated steam. Surplus product gas produced by the reformer is simply burned in the reformer boiler to raise additional export steam.

\section{Energy Recovery Subsystem}

The system employs product gas heat recovery. In order to augment thermal efficiency, upon exiting the particulate cyclones, the product gas is partially recirculated to the bed through a steam eductor, while the bulk of the product gas is processed through the heat recovery steam generator (HRSG). The heat absorbed by the water cooling of the pulsed heater tube sheet also contributes to the steam produced in the HRSG. Steam from the HSRG supplements the steam generated from the boiler.

The system utilizes a portion of the clean product gas for firing in the pulsed heaters. The flue gas leaving the superheater goes to the boiler where steam is generated. Excess product gas from the gas clean-up system is fired in the reformer boiler. Steam is distributed to the steam reformer subsystems as required with excess steam exported to the mill. 


\section{PROJECT ENVIRONMENTAL PROCESS}

Georgia-Pacific participated in the EPA Project XL process during the same period as the Engineering Study. Because the steam reformer technology has never been applied at a commercial scale, Georgia-Pacific needed assurance that we would not have to shut down the facility should the technology fail.

The U.S. Environmental Protection Agency (EPA), with the cooperation of State and local authorities, has initiated Project XL to work with interested companies or other potential Project Sponsors to develop innovative approaches to environmental protection. Project XL encourages potential sponsors to come forward with new approaches that can advance our nation's environmental goals more effectively and efficiently than current regulatory and policy tools or procedures. Project XL provides an opportunity for outside Parties, including local community and environmental groups, to be involved in the project. This "Stakeholder" process allows all interested individuals or groups to have input, voice concerns, and help shape the final project. Stakeholders for our agreement include: EPA, Virginia DEQ, Federal Land Manager, a local environmental group, and local concerned citizens.

This Final Project Agreement (Agreement or FPA) is a joint statement of the plans, intentions, and commitments of the U.S. Environmental Protection Agency (EPA), USDA Forest Service, Virginia Department of Environmental Quality (VADEQ), Georgia-Pacific Corporation, and other Stakeholders, to carry out this demonstration Project at Georgia-Pacific's Big Island, VA Facility. This Project will be part of EPA's Project XL program which promotes innovative approaches to environmental protection. This Agreement does not create legal rights or obligations and is not an enforceable contract or a regulatory action such as a permit or a rule. The previous statement applies to both the substantive and the procedural provisions of this Agreement. While the Parties to the Agreement fully intend to follow these procedures, this Agreement by itself does not legally obligate them to do so. Federal and State flexibility and enforceable commitments described in this Agreement will be implemented and become effective through a legal implementing mechanism such as a rule or permit. All Parties to this Agreement will strive for a high level of cooperation, communication, and coordination to assure successful, effective, and efficient implementation of the Agreement and the Project.

Our agreement allows the Big Island facility to construct a new recovery boiler after the regulatory compliance date, in the event the steam reformer technology fails.

The EPA Project XL Agreement associated with the Big Island Steam Reformer Project is a nonbinding document endorsed by the project stakeholders that describes the project application, technology innovation, positive environmental impacts, and other benefits. Additionally the Agreement outlines the required regulatory relief in order for the project to move forward. 


\section{LIQUOR TESTING}

Liquor testing was conducted in 3 phases. All of the tests were performed in StoneChem's Process Development Unit (PDU) in Baltimore, Maryland. StoneChem personnel performed all of the tests. The PDU consists of a liquor preparation system, liquor feed system, an indirectly heated fluidized bed steam reformer, two stages of gas clean-up cyclones, product gas thermal oxidizer, boiler, superheater, in-line gas chromatograph and instrumentation and controls.

\section{PHASE 1}

The Phase 1 test was conducted January 11 through February 4, 1999. This test was a follow-up to the preliminary testing conducted in 1998 by Georgia-Pacific. The Phase 1 liquor testing was an extended steam-reforming test using liquor from the Big Island mill. The objective of this test was to generate the design data for the design of the recovery system by running extended parametric tests of the liquor over a four-week period. The data collected would be the basis of the design and estimate for the full-scale demonstration plant at Big Island.

Two sequential tests were performed over the four-week period. The first test was conducted at $1,080^{\circ} \mathrm{F}$ and the second test was conducted at $1,124^{\circ} \mathrm{F}$. For both tests, liquor, bed solids and gas condensate samples were collected and analyzed. The steam reformer operated well during both tests with no evidence of agglomeration, defluidization or channeling in the bed and no heater fouling.

The test conducted at $1,080^{\circ} \mathrm{F}$ resulted in a carbon conversion of $81.3 \%$, a product gas higher heating value of 279 Btu per dscf air free and gas condensable hydrocarbon ("tar") yield of 6.7 gram per pound of black liquor solids. The test conducted at $1,124{ }^{\circ} \mathrm{F}$ resulted in a carbon conversion of $99.8 \%$, a product gas higher heating value of 253 Btu per dscf air free and gas condensable hydrocarbon ("tar") yield of 3.1 gram per pound of black liquor solids. ${ }^{3}$

\section{PHASE 2}

The Phase 2 test was conducted December 13 through 15, 1999. This test was designed to better determine the gas condensable hydrocarbon ("tar") yield and composition in the commercial facility. The tests were to evaluate the effect of a lower steam-to-black liquor carbon ratio on the production of hydrocarbons. This was done by operating the PDU at stable conditions using steam as a fluidizing medium, followed by a test using a "fixed gas" as the fluidizing medium. The "fixed gas" consisted of carbon dioxide, carbon monoxide, hydrogen, and nitrogen.

The tests were conducted at $1,120^{\circ} \mathrm{F}$ with liquor feed rate and fluidization velocity held constant. Due to a dry gas meter calibration error, StoneChem adjusted the gas condensable hydrocarbon values from the original raw data. The test with steam as the fluidizing medium resulted in gas hydrocarbon condensables (volatile organic compounds and semi- volatile organic compounds) of 2.3 gram per pound of black liquor solids. . The test with the fixed gas as the fluidizing medium resulted in gas hydrocarbon condensables of 7.2 gram per pound of black liquor solids.

\footnotetext{
${ }_{3}^{3}$ PulseEnhanced ${ }^{\mathrm{MM}}$ Steam Reforming Testing of $\mathrm{Na}_{2} \mathrm{CO}_{3} / \mathrm{NaOH}$ Spent Pulping Liquor, Report SC-0499-01-F, StoneChem, Inc., April, 1999
} 
These results clearly indicted an increase in the production of condensable hydrocarbons at the lower steam-to-black liquor carbon ratio. ${ }^{4}$

\section{PHASE 3}

The Phase 3 test was conducted January 19 through 12, 2001 after extensive modifications to the PDU. The PDU vessel freeboard was extended to achieve a gas residence time of approximately 13 seconds in the reactor vessel at operating temperature. In addition to the freeboard extension, a product gas recycle system was installed. This system consisted of a steam eductor (jet thermocompressor) with associated piping and controls. The tests were to better quantify the performance of the proposed commercial-scale steam reformer, particularly in respect to condensable hydrocarbon production.

The tests were conducted at an average bed temperature of $1,121^{\circ} \mathrm{F}$ with liquor feed rate and fluidization velocity held relatively constant. The test achieved a total carbon conversion of $98.5 \%$, consistent with previous test experience. The first pass residence time target for the vapor and gas phases was achieved ( 10.7 seconds actual vs. 13 seconds target). The steam partial pressure (12.2 psia) was slightly higher than anticipated. This was the result of limited liquor throughput due to the added heat loss in the new gas recycle system. This test produced a gas condensate with a total organic loading of 2.0 grams per pound black liquor solids.

The results of all the PDU tests on the liquor from the Big Island process were analyzed as related to the formation of organic components that would be discharged in the wastewater effluent from the proposed full-scale system. The analysis indicated a maximum predicted yield of gas condensate organics of 3.3 grams per pound of black liquor solids for the full-scale system. This predicted yield is considered a high and worse case. ${ }^{5}$ The Phase 3 tests did not show any significant effect of increased retention time or gas recycle on the yield of gas condensate organics.

\footnotetext{
${ }^{4}$ PulseEnhanced ${ }^{\mathrm{TM}}$ Steam Reforming Steam-to-Carbon Ratio Test, Report SC-0100-01-F R3, StoneChem, Inc., January, 2000

${ }^{5}$ PulseEnhanced ${ }^{\text {TM }}$ Steam Reforming PDU Gas Recycle Modifications \& Liquor Test, Report SC-0301-01-F R1, StoneChem, Inc., March, 2001
} 


\section{PROJECT SCHEDULE \& COST}

The results of the study indicated there is no significant difference in the implementation time for the steam reforming chemical recovery system as compared to installing a recovery boiler system. The implementation time for the first demonstration will be significantly longer due to the extended commissioning time required for the new technology. Future projects will not require this extended period and will therefore require similar engineering, construction and start-up times. The project timeline is shown below.

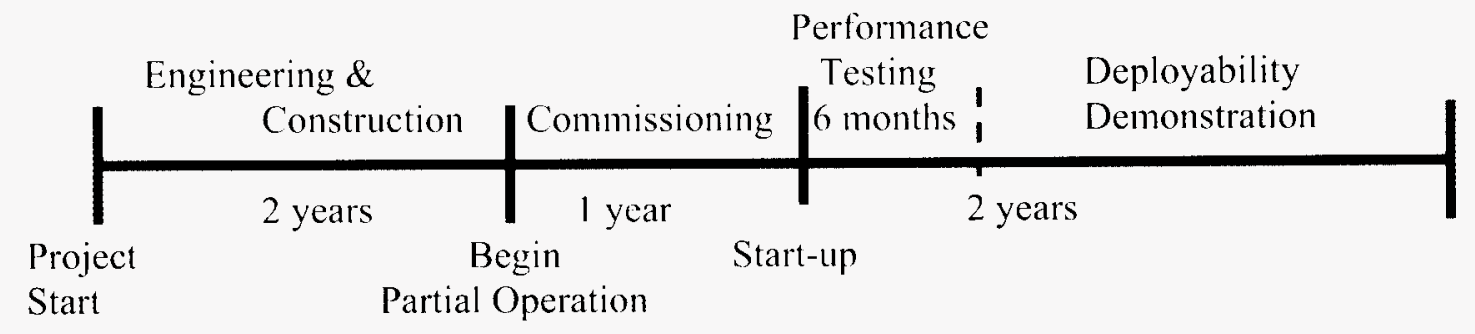

The study performed an engineering estimate of the cost to install the steam reforming chemical recovery technology as well as the recovery boiler technology. The cost of installing this first steam reforming chemical recovery system is $54 \%$ higher than for the equivalent recovery boiler system. The chart below provides the cost comparison.

\begin{tabular}{r|c}
$\%$ of Recovery Boiler Cost to \\
Implement Reformer Technology \\
Total Direct Cost & $146 \%$ \\
Contractor Indirect & $67 \%$ \\
Training/Sales Tax/Spares & $127 \%$ \\
Engineering/Construction Management & $142 \%$ \\
Eng / Costs/Temp Facilities/Freight/Insurance & $173 \%$ \\
Erection Supervision/Testing / Inspection/Escalation & $120 \%$ \\
\hline Contingency Required & $273 \%$ \\
Total Capital Cost & $154 \%$ \\
\hline
\end{tabular}




\section{VIABILITY}

The overall results of the study indicated that installation of a steam reforming chemical recovery system was higher than the cost as an equivalent recovery boiler system. A significant portion of this cost is attributed to this being the first demonstration size project. Future projects are expected to be more cost effective due to the lessons learned from this project. The energy efficiency of the reformer system was better than the recovery system, while the environmental performance appeared to surpass the recovery boiler system. The technological risk and project risk associated with the installation of the reformer system were significantly higher for the reformer system. In February 2001, Georgia-Pacific submitted a proposal to DOE for the implementation of the demonstration project. Based on the findings of the Engineering Study and selection of this project for co-funding by DOE, Georgia-Pacific elected to go forward with a project for the demonstration of the technology.

After completion of the Engineering Study, additional engineering was performed as part of the Demonstration Project. This engineering effort identified several technology gaps that will be discussed in the following section. Also identified were several areas where modifications would be required for the project. The major changes included:

- compressed air system for start-up

- additional liquor storage capacity required

- Flue Gas Recirculation system for the pulsed heaters

- modification of the product gas clean-up system

- demineralized quality feedwater for the pulsed heaters

After evaluation of the impact of these changes, Georgia-Pacific submitted an application in October, 2001 to continue the project. The application was accepted and approved by DOE in November, 2001. 


\section{TECHNOLOGY GAPS}

During and after the engineering study, several areas were identified where additional fundamental research would be beneficial. These are areas where the process requires additional engineering in order for companies to be able to assess the commercial viability of the technology:

- formation (species \& quantity) and destruction (or treatment of effluent streams) of noncondensable hydrocarbons (tars)

- testing or modeling of environmental emissions of pulse heaters burning various product gases and fuels

- effects on refractory of sodium migration (or other chemicals) from a granular sodium carbonate bed at $1100-1200 \mathrm{deg}$. F - expected life of various refractories

- reformer vessel design studies (cylindrical vs. rectangular cross section, hot wall vs. cold wall, SS or chrome containing steel vs. carbon steel, bed fluidization properties, channeling \& bubble formation)

- agglomeration of bed solids due to long term exposure to heat of $1100-1200 \mathrm{deg}$. F

- metals research for pulse heater tubes \& tube shields burning low \& high H2S containing product gas

- pulse heater design studies (water cooling circuit and scale formation, heater size scaleup - longer heaters, different tubes, fins)

- $\mathrm{H} 2 \mathrm{~S}$ absorption research for high $\mathrm{CO} 2$ containing product gas and hot gas clean-up technologies

- flammability studies of product gas in a steam environment

- study of the economics of compressing reformer product gas for use in combined cycle vs. pressurizing the entire system

- development or modification of a small pilot test set-up similar to the laminar entrained flow reactor to allow for reactions to occur at the lower steam reforming temperatures current test facility is too costly for extensive R\&D testing 